\title{
A unique mating strategy without physical contact during fertilization in Bombay Night Frog (Nyctibatrachus humayuni) with the description of a new form of amplexus and female call
}

Bert Willaert, Robin Suyesh, Sonali Garg, Varad B Giri, Mark A Bee, SD Biju

Anurans show the highest diversity in reproductive modes of all vertebrate taxa, with a variety of associated breeding behaviours. One striking feature of anuran reproduction is amplexus. During this process, in which the male clasps the female, both individuals' cloacae are juxtaposed to ensure successful external fertilization. Several types of amplexus have evolved with the diversification of anurans, and secondary loss of amplexus has been reported in a few distantly related taxa. Within Nyctibatrachus, a genus endemic to the Western Ghats of India, normal axillary amplexus, a complete loss of amplexus, and intermediate forms of amplexus have all been suggested to occur, but many species remain unstudied. Here, we describe the reproductive behaviour of $N$. humayuni, including a new type of amplexus. The dorsal straddle, here defined as a loose form of contact in which the male sits on the dorsum of the female prior to oviposition but without clasping her, is previously unreported for anurans. When compared to known amplexus types, it most closely resembles the form of amplexus observed in Mantellinae. Furthermore, we prove that, opposed to the situation in most anurans, male semen release happens before egg deposition. We hypothesize that the male ejaculates on the female's dorsum and that sperm subsequently runs from her back and hind legs before fertilizing the eggs. A second feature characterizing anuran breeding is the advertisement call, mostly produced solely by males. Despite recent descriptions of several new Nyctibatrachus species, few studies have explored their vocal repertoire. We describe both the male advertisement call and a female call for $N$. humayuni. The presence of a female call has not been reported within Nyctibatrachidae, and has been reported in less than $0.5 \%$ of anuran species. Altogether, our results highlight a striking diversity and several unique aspects of Nyctibatrachus breeding behaviour. 
1 A unique mating strategy without physical contact during fertilization in Bombay Night Frog

2 (Nyctibatrachus humayuni) with the description of a new form of amplexus and female call 3

4 Bert Willaert ${ }^{1}$, Robin Suyesh ${ }^{2}$, Sonali Garg ${ }^{2}$, Varad B Giri ${ }^{3}$, Mark A. Bee ${ }^{4}$ and SD Biju² 5

$6 \quad{ }^{1}$ Rostraat 9, 9850 Hansbeke, Belgium

$7 \quad 2$ Systematics Lab, Department of Environmental Studies, University of Delhi, Delhi 110007 , 8 India

$9 \quad{ }^{3}$ National Centre for Biological Sciences, TIFR, Bangalore 560 065, India

$10{ }^{4}$ Department of Ecology, Evolution, and Behavior, University of Minnesota-Twin Cities, St.

11 Paul, Minnesota, United States of America

12

13

14 Corresponding Authors:

15

16

Bert Willaert ${ }^{1}$

17 Rostraat 9, 9850 Hansbeke, Belgium

18 Email address: bert.willaert@gmail.com

19

SD Biju ${ }^{2}$

21 Systematics Lab, Department of Environmental Studies, University of Delhi, Delhi 110 007, 22 India

23 Email address: sdbiju.du@es.du.ac.in 


\section{ABSTRACT}

35 Anurans show the highest diversity in reproductive modes of all vertebrate taxa, with a variety of 36 associated breeding behaviours. One striking feature of anuran reproduction is amplexus. During this process, in which the male clasps the female, both individuals' cloacae are juxtaposed to ensure successful external fertilization. Several types of amplexus have evolved with the diversification of anurans, and secondary loss of amplexus has been reported in a few distantly related taxa. Within Nyctibatrachus, a genus endemic to the Western Ghats of India, normal axillary amplexus, a complete loss of amplexus, and intermediate forms of amplexus have all been suggested to occur, but many species remain unstudied. Here, we describe the reproductive behaviour of $N$. humayuni, including a new type of amplexus. The dorsal straddle, here defined as a loose form of contact in which the male sits on the dorsum of the female prior to oviposition but without clasping her, is previously unreported for anurans. When compared to known amplexus types, it most closely resembles the form of amplexus observed in Mantellinae. Furthermore, we prove that, opposed to the situation in most anurans, male semen release happens before egg deposition. We hypothesize that the male ejaculates on the female's dorsum and that sperm subsequently runs from her back and hind legs before fertilizing the eggs. A second feature characterizing anuran breeding is the advertisement call, mostly produced solely by males. Despite recent descriptions of several new Nyctibatrachus species, few studies have explored their vocal repertoire. We describe both the male advertisement call and a female call for N. humayuni. The presence of a female call has not been reported within Nyctibatrachidae, and has been reported in less than $0.5 \%$ of anuran species. Altogether, our results highlight a striking diversity and several unique aspects of Nyctibatrachus breeding behaviour.

Subjects Animal Behaviour, Zoology, Ecology attendance, Egg predation, Nyctibatrachidae, Reproductive modes, Western Ghats 


\section{INTRODUCTION}

63 Anurans exhibit considerable diversity in their reproductive modes, with differences occurring,

64 for example, in oviposition sites, larval development, and parental care (Crump, 1974; Haddad 65 \& Prado, 2005; Crump, 2015). One behaviour characteristic of nearly all anuran species' 66 reproduction is amplexus. This behaviour, whereby the male takes the female in an embrace, is considered to have evolved to optimize successful fertilization of the eggs. Because fertilization is external in most anurans, the juxtaposition of the male and female cloacae during amplexus helps to synchronize egg deposition and the release of sperm (Duellman \& Trueb, 1986: 68-70; Wells, 2007: 452-458). Several forms of amplexus have been described, with inguinal and axillary being the most widespread. Inguinal amplexus, in which the male clasps the female around her waist, is considered the ancestral state and is found in the oldest anuran lineages (Duellman \& Trueb, 1986: 68-70; Wells, 2007: 452). Axillary amplexus, in which the male grasps the female in her armpits, is sometimes considered to be more efficient because the cloacae are better juxtaposed (Rabb \& Rabb, 1963). While there is no evidence that axillary amplexus results in higher fertilization rates than inguinal amplexus, species with axillary amplexus may require less time to lay their eggs, thereby reducing an amplectant pair's vulnerability to predators (Wells, 2007: 456). Other forms of amplexus, in addition to axillary amplexus and inguinal amplexus, have evolved in some lineages (Duellman \& Trueb, 1986: 6870). A complete loss of amplexus has been observed in a few distantly related taxa (Limerick, 1980; Kunte, 2004; Zhang et al., 2012).

Another distinctive behaviour associated with anuran reproduction is calling. The vocal repertoire of male frogs and toads is well known, with the advertisement call, which is produced to attract mates and signal presence towards other males, being present in all but a few species (Wells \& Schwartz, 2007). Male advertisement calls are species specific and can convey information about the signaller to other individuals. A key function of male advertisement calls is in premating species isolation (Gerhardt \& Huber, 2002). It is, therefore, important to record and describe advertisement calls, as they can provide useful information in both taxonomical and evolutionary frameworks. Female calls are less well known because they are rare and seldom observed. For example, females in only a few anuran species are known to produce true advertisement calls (e.g., Emerson, 1992; Bush, Dyson \& Halliday, 1996; Bush, 1997; Bosch \& Márquez, 2001). The use of courtship calls by females engaged in close-range interactions with 
93 males has been reported in a number of species (e.g., Given, 1993; Tobias, Viswanathan \& 94 Kelley, 1998; Bosch, 2002; Shen et al., 2008; Cui et al., 2010). In some species, females produce 95 a territorial call upon disturbance (Capranica, 1968; Wells, 1980; Stewart \& Rand, 1991). 96 Females in some anuran species also produce a release call when they are amplexed but 97 unreceptive, or amplexed by an undesired male (Brzoska, Walkowiak \& Schneider, 1977; 98 Gollmann, Benkö \& Hödl, 2009).

99 The genus Nyctibatrachus Boulenger, 1882 is endemic to the Western Ghats of India and 100 comprises 28 known species, many of which have only recently been described (Das \& Kunte, 101 2005; Biju et al., 2011; Gururaja et al., 2014; Frost, 2015). Nyctibatrachus species vary in 102 snout-vent length (SVL) from $10.0 \mathrm{~mm}$ (N. minimus Biju et al., 2007) to $76.9 \mathrm{~mm}$ (N. grandis 103 Biju et al., 2011) and are either stream-associated or found in the leaf litter, the latter making use 104 of small puddles for reproduction (Biju et al., 2007; Biju, et al., 2011; Van Bocxlaer et al., 2012).

105 Information about their natural history is scarce, and the conservation status of many species is 106 unknown, with only 15 out of the 28 species having been assessed by the IUCN Red List 107 (including four that are considered data deficient) (Biju et al., 2011; IUCN, 2014). Furthermore, 108 male advertisement calls have only been described in four species (Kuramoto \& Joshy, 2001; 109 Gururaja et al., 2014).

110 Despite their poorly understood ecology, several studies suggest the presence of 111 interesting forms of reproductive behaviour (Kunte, 2004; Biju et al., 2011; Gramapurohit, 112 Gosavi \& Phuge, 2011; Gururaja et al., 2014). In all Nyctibatrachus species, egg clutches are 113 deposited on rocks or vegetation overhanging water, and tadpoles fall in the water after hatching, 114 where they continue their development and metamorphosis (Biju et al., 2011; Gururaja et al., 115 2014). Different kinds of amplexus behaviours have been described within this genus. Pairs of $N$. 116 kumbara Gururaja et al., 2014, for example, perform a short axillary amplexus followed by a 117 handstand. The female then deposits the eggs from this upside down position directly after the 118 male has dismounted (Gururaja et al., 2014). Afterwards, males of N. kumbara cover the 119 deposited eggs with a layer of mud, a behaviour previously unknown for anurans. In N. aliciae 120 Inger et al., 1984, N. humayuni Bhaduri \& Kripalani, 1955, N. jog Biju et al., 2011 and N. minor 121 Inger et al., 1984 a short, loose physical contact between the male and female takes place as the 122 male sits on the dorsum of the female but does not clasp her as in a normal axillary amplexus 123 (Biju et al., 2011; Gramapurohit, Gosavi \& Phuge, 2011). In other species, such as N. petraeus 
124 Das \& Kunte, 2005, amplexus behaviour may be completely absent, with the female depositing 125 the eggs prior to the male fertilizing them (Kunte, 2004; Das \& Kunte, 2005). On one occasion, 126 amplexus was observed in $N$. petraeus five minutes before egg deposition took place, and the 127 author therefore considered this to be a type of 'pseudo-amplexus' (Kunte, 2004).

128 Together the available data indicates a wide range of breeding-associated behaviours in 129 Nyctibatrachus, with a new form of amplexus and an intrageneric variation in amplexus types 130 previously unreported in anurans. To better understand the reproductive behaviour of

131 Nyctibatrachus frogs, we observed breeding and associated vocalizations in a wild population of $132 N$. humayuni. Here, we describe both the male advertisement call and a female call, and discuss 133 the different behavioural steps involved in reproduction based on field observations.

\section{MATERIALS AND METHODS}

136 Field surveys and behavioral observations

137 We spent a total of 40 nights in the field during July and August 2010 and 2012 studying a 138 population of Nyctibatrachus humayuni. The population was located in a dense forest near 139 Humbarli village, Koyna, Satara District, Maharashtra (coordinates 17²4’10.8” N, 140 7344'13.2”E, $827 \mathrm{~m}$ asl) (Fig. S1A). Males were easily located by their calls while females, 141 which were harder to find, were more often encountered by chance. Sex was determined by the 142 presence of femoral glands in males and their absence in females (Biju et al., 2011). The moment 143 a female was observed approaching a male, we started filming the event using a camera with 144 infrared function (Sony HDR-XR 550VE). In most such instances, we used infrared light to 145 avoid disturbing the animals and affecting their behaviour. Movies were analysed with iMovie 146 8.0.6 (Apple Inc.) to determine the duration of different steps of reproduction. In order to test the 147 assumption that fertilization happens after the female has left the oviposition site (Gramapurohit, 148 Gosavi \& Phuge, 2011), Ziploc ${ }^{\circledR}$ bags were placed around egg clutches directly after deposition 149 on five occasions to hinder male contact with the eggs. To determine the duration of embryo 150 development, deposited and fertilised clutches were monitored every evening until hatching 151 occurred.

152

153 Call recording 
154 The advertisement calls of eight males and the calls of one female were recorded on a solid-state 155 digital recorder (Marantz PMD620, 44.1 KHz sampling rate, 16-bit resolution) using a 156 directional shotgun microphone (Sennheiser ME 66). A minimum of 20 calls were recorded per 157 individual. Microphones were handheld and positioned at a distance of approximately $75 \mathrm{~cm}$ 158 from the target animal. Sounds were monitored in real time using headphones (Sony MDR159 V500). At the end of each recording, the calling individual was captured and its SVL was 160 measured to the nearest $0.1 \mathrm{~mm}$ using digital callipers. A portable digital balance was used to 161 measure body mass to the nearest $0.01 \mathrm{~g}$. These two measures of body size were used to compute 162 a measure of body condition (i.e., length independent mass) following Baker (1992). Condition 163 was estimated as the residuals from a regression of the cube root of mass on SVL divided by 164 SVL.We used these measures of SVL body mass and body condition to assess whether any call properties were correlated with body size and condition. Recorded frogs were released at their

166 calling site immediately after obtaining body size measurements. To avoid recording the same 167 individual twice, we only recorded animals that were widely spaced $(>15 \mathrm{~m})$. Since the study area was large (ca. $250 \mathrm{~m} \times 30 \mathrm{~m}$ ) and males of this species are territorial, being found sitting next to or on previously deposited egg clutches on subsequent nights, the chance of recording the same individual multiple times was negligible (Gramapurohit, Gosavi \& Phuge, 2011). As call properties can vary with temperatures in anurans (Gerhardt \& Huber, 2002), we recorded both

172 dry bulb and wet bulb air temperatures $\left( \pm 0.2^{\circ} \mathrm{C}\right)$ at the animal's calling site using a thermometer 173 (Jennson Delux).

174 This study was conducted with permissions and guidelines from the responsible 175 authorities in the State Forest Department of Maharashtra. Study permit: D-22 176 (8)/Research/4543/2012-13, dated 1-03-2012. This study did not sample animals for any captive 177 or laboratory studies. All observations were made in the wild. Recorded frogs were released back 178 at their calling site immediately after measuring the body size and body mass.

180 Call analysis

181 We used Raven Pro 1.4 (Charif, Waack \& Strickman, 2010) to measure 32 acoustic properties 182 for each of the 160 advertisement calls recorded from the eight males. Raven's waveform display 183 was used to measure 21 temporal properties, while 11 spectral properties were measured using 184 the spectrogram slice view (1024pt. FFT, Hanning window). A description of the measured 
185 properties is provided in Table S1A. Properties are analyzed after Bee et al. (2013a; 2013b). 186 Coefficients of variation $(\mathrm{CV}=$ standard deviation/mean) were computed to describe patterns of 187 both within-individual $\left(\mathrm{CV}_{\mathrm{w}}\right)$ and between-individual $\left(\mathrm{CV}_{\mathrm{b}}\right)$ variation in call parameters and are 188 expressed her as percentages (Gerhardt, 1991). Correlation of any of the acoustic parameters 189 with physical characteristics (SVL, body mass and body condition) and temperature was 190 explored by performing Spearman rank correlations using the software package Statistica v7.1 191 (Statsoft). Due to the low sample size, these correlation analyses should be considered 192 exploratory and are not intended to test any specific hypotheses. Five temporal and four spectral 193 properties were measured for the 20 calls recorded from one female (Table S1B). Since we only 194 recorded the call of a single female, descriptive statistics and correlations with other parameters 195 could not be carried out.

196

\section{RESULTS}

198 Reproductive behaviour

199 Breeding took place in and around a stream in which the water level heavily depended on the 200 weather conditions (Figs. S1B and S1C). Males were observed calling from different positions 201 along the stream. They were perched on rocks, vegetation and fallen trees, all bordering or 202 overhanging the water (Video S1). Their vertical position ranged from partially submerged to up 203 to four metres high on trees. Females were observed moving slowly between the territories of 204 different males. A schematic overview of the reproductive sequence is shown in Figures 1 and 2 , 205 and videos of the different steps are provided as supplementary information. 

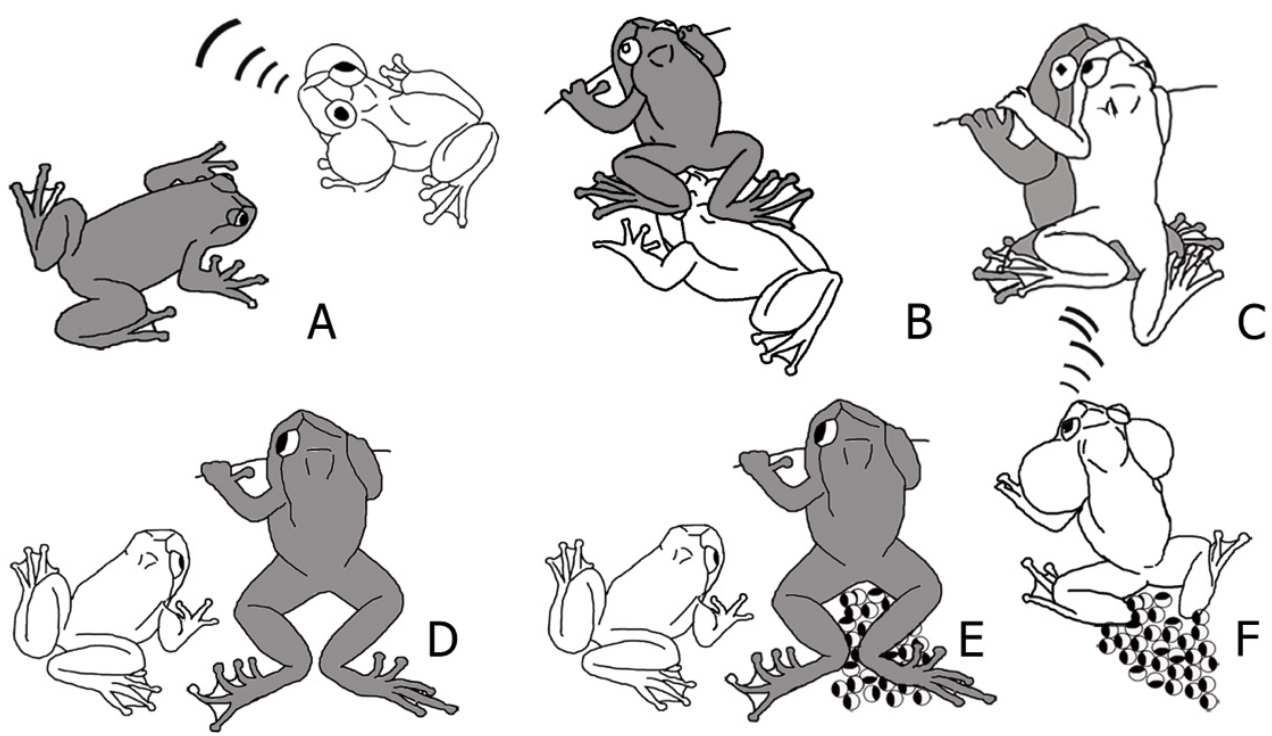

Figure 1 Schematic sequence of reproductive behaviour in Nyctibatrachus

humayuni. (A) A female approaches a calling male. (B) The female sits in front of the male and creeps backwards, until her feet touch the male's head. (C) The male mounts the female and forms a dorsal straddle, and most likely sperm is released on her back during this moment. (D) When the female is about to deposit the eggs, the male dismounts. (E) Immediately after the male dismounts, the female deposits the eggs and remains motionless with her hind legs stretched around the eggs. (F) After oviposition, the female leaves the oviposition site, and the male sits on or near the eggs and continues to call. The male is drawn white and the female grey.

When a female approaches a male (Figs. 1A and 2A; Video S2), she sits in front of him and creeps backwards until her abdomen is placed over his head, making physical contact (Figs. $1 \mathrm{~B}$ and 2B; Video S3). At this moment, the male mounts the female. If the male does not react, the female will repeat this physical contact. When mounted, the male rests on the female without grabbing her in a firm amplexus, and instead uses his hands to hold on to the leaf or branch on

211 which the pair sits (Figs. 1C and 2C; Video S4). Lateral movements in the male's flank were 212 observed during this stage in a few of the breeding sequences (Video S4). This loose form of 213 amplexus is of short duration, lasting on average $768 \mathrm{~s}(\mathrm{n}=21$, range: $338-1670 \mathrm{~s})$. At the end of 214 this embrace, the female strongly and repeatedly arches her back followed by the male 215 immediately dismounting (Fig. 1D; Video S5), a behaviour known from other species too 216 (Gosner \& Rosmann, 1959). The female deposits eggs in a single bout immediately after the 217 male dismounts (Figs. 1E and 2D; Video S6). Oviposition takes only a few seconds and occurs 
218 without any form of physical contact between the sexes. The female then remains motionless, 219 with her hind legs stretched around the freshly deposited clutch (Figs. 1E and 2D; Video S6). It 220 takes on average $479 \mathrm{~s}(\mathrm{n}=17$, range: $260-961 \mathrm{~s})$ before the female moves after egg laying. After

221 this first movement, it takes another $728 \mathrm{~s}(\mathrm{n}=11$, range: 405-1692 s) before she jumps back into 222 the stream. During this period, the male is sitting nearby. There is, however, no physical contact 223 between the two sexes after egg deposition.
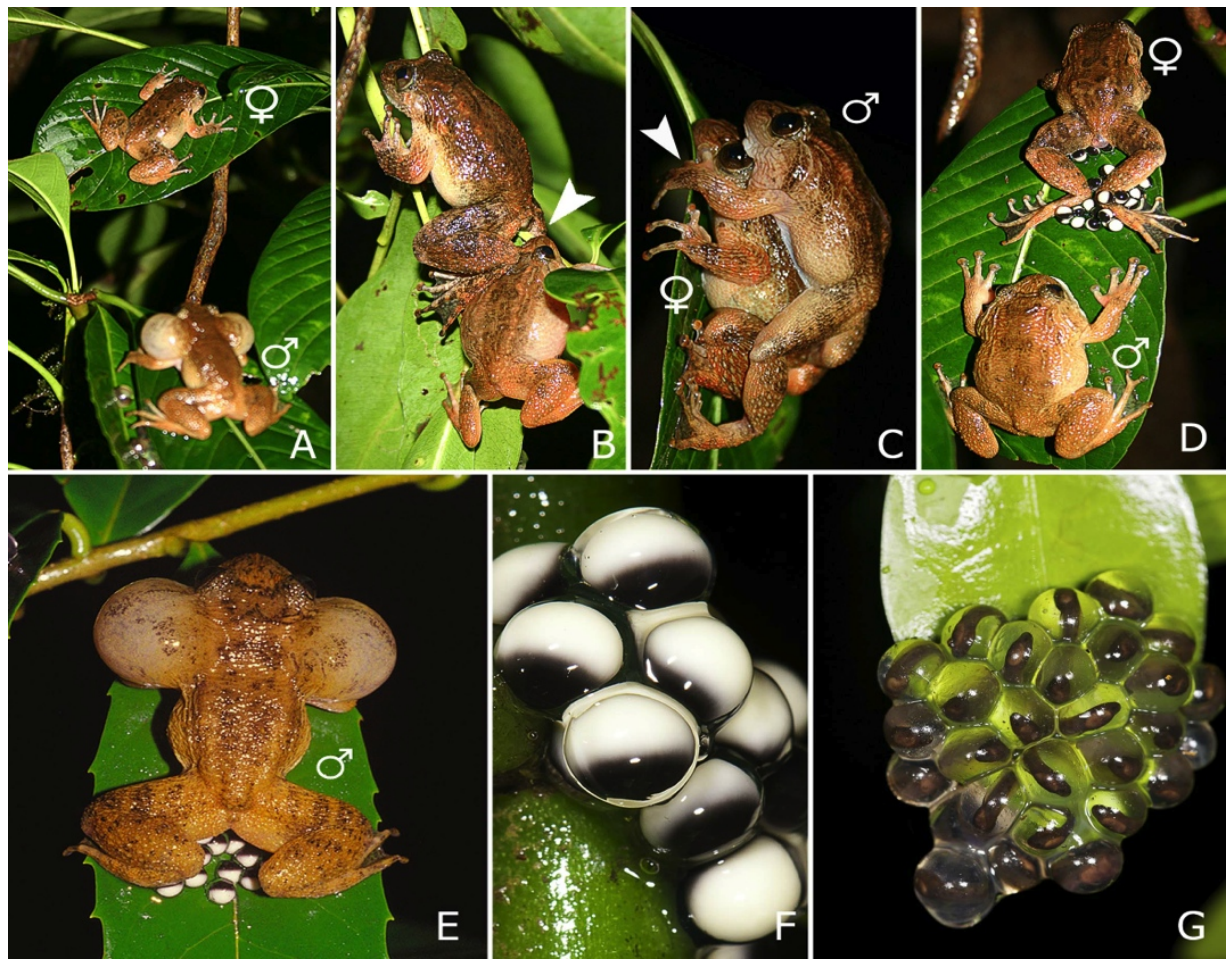

Figure 2 A-E. Sequence of breeding behaviour in Nyctibatrachus humayuni;

F-G. Egg development. (A) Female approaches a calling male. (B) Female touches male just before the dorsal straddle (arrow indicates the position of female's leg on male's head). (C) Male mounts the female in a dorsal straddle, and most likely sperm is released on her back during this moment (arrow indicates the male's hand positioned on the leaf, but not clasping the female). (D) Female deposits eggs and remains motionless with her hind legs stretched around the eggs. The male is mostly seen sitting close-by without any physical contact with the female. (E) After the female leaves the oviposition site, the male sits on or near the eggs and continues to call. (F) Freshly laid eggs, pigmented (egg diameter $3.5 \pm 0.2 \mathrm{~mm}, \mathrm{n}=20)$. (G) Developing embryos on the $19^{\text {th }}$ day, just 
before hatching out of the eggs.

225 During several of the observed breeding sequences, the male crawled back over the eggs 226 after the female had moved away (Figs. 1F and 2E), but we did not see this on every occasion. 227 This prompted us to test whether fertilization had already happened during an earlier stage. We 228 tested this by placing a Ziploc ${ }^{\circledR}$ bag around five egg clutches directly after deposition, and in this 229 way prevented the male from having any further contact with the eggs (Video S7). Interestingly, 230 in all five clutches, the fertilization rate was $100 \%$. In at least half of the observations we made 231 (nine observations), reproduction was interrupted by one or both of the frogs falling into the 232 water (Video S6, examples 6 and 7). Fallen individuals returned to the same position to continue 233 the mating sequence, except when strong currents swept them away. Males showed high site 234 fidelity, with new eggs being deposited directly next to present clutches or in close vicinity $(\leq 50$ $235 \mathrm{~cm})$. When a female approached a male calling from a position away from his previously 236 fertilized clutches, the male moved towards those eggs upon the first contact while continuing to 237 produce advertisement calls as the female followed. Males are known to defend their territories 238 (Gramapurohit, Gosavi \& Phuge, 2011), and we witnessed a single event of aggression where 239 the resident male chased off an intruder (Video S8).

240 We monitored 15 egg clutches from the moment of deposition until hatching. Of the 15 241 clutches, 12 were eaten before hatching took place. These cases of predation were rarely 242 observed but could easily be distinguished from hatched clutches, because in hatched clutches, 243 the jelly remained visible on the substrate after hatching, in contrast to instances of predation, 244 where most of the jelly was removed. In one of the remaining three clutches, hatching started 18 245 days after oviposition and all larvae had fallen into the stream by the $19^{\text {th }}$ day. In the other two 246 clutches, hatching started after 19 days and finished one and two days later (Figs. 2F and 2G).

248 Male advertisement calls

249 Male advertisement calls are composed of two distinct parts, with the first part being non250 pulsatile and the second part having a pulsatile temporal structure (Fig. 3A; Audios S1 and S2).

251 A detailed overview of analysed properties, including the variation both within and between 252 individuals, is given in Table S2. 
The mean call duration was $532 \mathrm{~ms}$ (range: 483-630 ms). On average, calls reached their full amplitude in $268 \mathrm{~ms}$ (rise time) and decreased in amplitude over the last $262 \mathrm{~ms}$ of the call 255 (fall time). Both rise time and fall time were approximately $50 \%$ of the total call duration (Table S2A). The second part of calls consisted of 16-24 pulses, with a mean pulse period of $13.2 \mathrm{~ms}$ and a mean pulse duration of $12.8 \mathrm{~ms}$. These pulses were produced at rates of 74-84 pulses/s. Individual pulses had mean rise and fall times of $4.7 \mathrm{~ms}$ and $8.1 \mathrm{~ms}$, respectively (Table S2C).
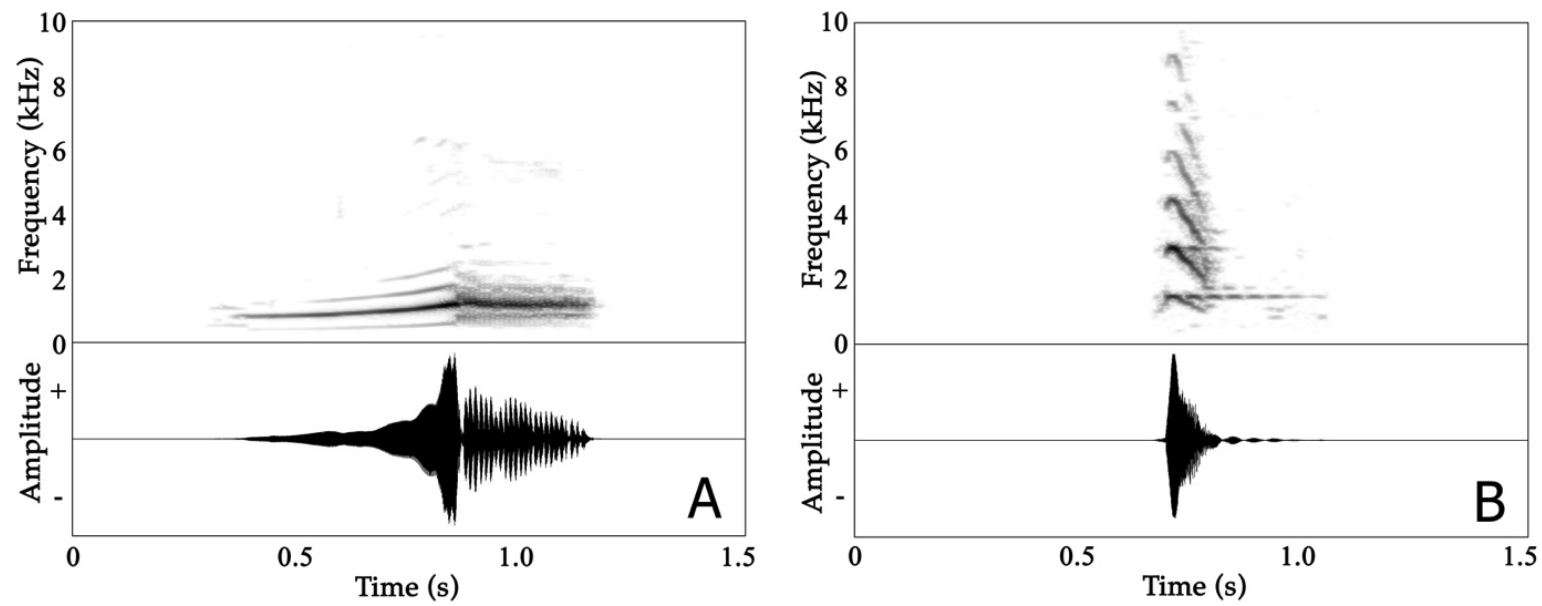

Figure 3 Spectrograms (above) and oscillogram (below) of Nyctibatrachus humayuni calls. (A) Male advertisement call. (B) Female call.

The mean dominant frequency, measured over entire calls, was $1.34 \mathrm{kHz}(1.11-1.45 \mathrm{kHz})$ with relatively low variation between calls produced by the same individual $\left(\mathrm{CV}_{\mathrm{w}}=3.73 \%\right)$ compared to the magnitude of variation observed among the eight individuals $\left(\mathrm{CV}_{\mathrm{b}}=8.19 \%\right)$. The dominant frequency of the first, non-pulsatile part of the call ranged between $0.91-1.45 \mathrm{kHz}$ while in the second, pulsatile part the dominant frequency ranged between $1.17-1.47 \mathrm{kHz}$ (as calculated from first pulse, middle pulse and last pulse) (Table S2). Frequency modulation is present in the first, non-pulsatile part of the call, but absent in the second, pulsatile part. The dominant frequency increased by approximately 30\% during the first part of the call, from 1027 $\mathrm{Hz}$ (mean dominant frequency 1) to $1336 \mathrm{~Hz}$ (mean dominant frequency 4) in less than $300 \mathrm{~ms}$ 271 (Table S2B).

Results of correlation tests are presented in Table S3. SVL and body mass of the different recorded males and corresponding temperature data is presented in Table S4. The mean ( \pm SD) dry bulb and wet bulb air temperatures during our study were $22.2 \pm 0.6^{\circ} \mathrm{C}$ and $22.7 \pm 0.4^{\circ} \mathrm{C}$, respectively. There were no correlations between these temperatures and the acoustic properties analysed. Though temporal properties are frequently correlated with temperature, we attribute 
277 this lack of temperature effects on call properties to the very small temperature variation across 278 our recordings $\left(<2.1^{\circ} \mathrm{C}\right.$ dry bulb air temperature; $<1.1^{\circ} \mathrm{C}$ wet bulb air temperature).

279 Several spectral properties were correlated with our measures of body size. The overall 280 dominant frequency of the entire call was significantly negatively correlated with body mass 281 (Table S3A). The dominant frequencies measured separately over the first and second halves of 282 the call were also significantly negatively correlated to body mass (Tables S3B and S3C). The 283 overall dominant frequency of the entire call was also negatively correlated with the SVL (Table 284 S3A). The overall dominant frequency, dominant frequency 2, and dominant frequency 4 of the $2851^{\text {st }}$ half were significantly negatively correlated with SVL (Table S3B). The overall dominant 286 frequency and dominant frequency of the first and last pulses of the second, pulsatile part of the 287 call were also significantly negatively correlated with SVL (Table S3C). The correlation of 288 dominant frequency 1 and dominant frequency 3 with SVL were marginally non-significant in the first half of the call (Table S3B). Only one temporal property, pulse 50\% rise time of maximum amplitude pulse, was correlated with body mass (Table S3C).

With only one exception, there were no significant correlations between body condition and the acoustic properties measured in this study (Table S3). The exception was the temporal property of fall time of the first part of the call, which was significantly negatively correlated with body condition (Table S3B). Several spectral properties had reasonably strong negative correlations with body condition $(-0.69 \leq r \leq-0.62)$, but these correlations were not quite significant $(0.06 \leq P \leq 0.10$; Table $\mathrm{S} 3 \mathrm{~B})$. Body condition can sometimes be strongly related to certain temporal call properties associated with higher energetic demands, such as fast pulse rates (Jakob et al., 1996). Although overall pulse rate was not related to body condition (Table S3C), two measures of individual pulse period $(=1 /$ pulse rate) had correlations with body mass that approached significance $(r=-0.69, P=0.06$; Table S3C). We attribute the general lack of significant effects of body condition on several analysed call properties to our small sample size.

302

303 Female call

304 Female Nyctibatrachus humayuni calls were only rarely observed (four individuals), as females 305 do not seem to vocalize on a regular basis. A single female calling from a height of $2.5 \mathrm{~m}$ above the ground was recorded. It produced about 50 calls in about 30 minutes. These calls sounded 
308 quite distinct from the male advertisement call (Fig. 3B; Audio S3; Video S9). The call is short,

309 consisting of a single note, with a mean call duration of $83 \mathrm{~ms}$ and a rapid onset (call rise time $=$

$31016 \mathrm{~ms}$ ). The call's frequency spectrum is characterized by several frequency peaks, with the

311 lowest three peaks having mean frequencies of $1.45 \mathrm{kHz}$ (Dominant frequency 1), $2.90 \mathrm{kHz}$

312 (Dominant frequency 2) and $4.37 \mathrm{kHz}$ (Dominant frequency 3), respectively. The overall

313 dominant frequency of the call was $2.85 \mathrm{kHz}$ (range 1.39-3.10 kHz). Based on measures of

314 within-individual CVs, spectral properties were less variable $\left(2.53 \leq \mathrm{CV}_{\mathrm{w}} \leq 12.37 \%\right)$ compared

315 to temporal properties $\left(18.30 \leq \mathrm{CV}_{\mathrm{w}} \leq 58.04 \%\right)$. The call $50 \%$ rise time and call $50 \%$ fall time

316 were more variable compared to other temporal properties. During two of our observations of

317 female calling behaviour in $N$. humayuni, the female only initiated calling when she had not

318 succeeded in reaching a calling male after trying for considerable time (more than 30 minutes).

319 On one of these occasions the male immediately changed his position as soon as the female

320 called. Although the male's response resulted in him calling from a new position closer to the

321 stream and to the female, she still failed to locate him.

322

\section{DISCUSSION}

324 New form of amplexus

325 The loose amplexus observed here in Nyctibatrachus humayuni differs from all previously 326 described amplexus types in anurans (Duellman \& Trueb, 1986: 68-70) (Figs. 4A-F). Our 327 observations indicate there is some similarity between amplexus in $N$. humayuni and that 328 observed in some mantellid frogs, whereby the male sits with his abdomen on the female's head 329 (Blommers-Schlösser, 1975; Glaw \& Vences, 2007: 144, 186, 200, 204; Altig, 2008). Duellman

$330 \&$ Trueb (1986: 69) defined this type of amplexus as a straddle, and it was later more specifically 331 called a head straddle (Savage, 2002: 166). The form of contact described in this study resembles 332 this head straddle, but the male is positioned lower on the female, with his abdomen placed on 333 her lower dorsum. When mounted, the male rests on the female without grabbing her tightly, but 334 instead uses his hands to hold on to a leaf, branch or tree trunk (Figs. 1C, 2C and 4J-K). On 335 some occasions his hands may rest on her arms or hands (Figs. 4H-I). Gramapurohit et al. 336 (2011) considered this to be cephalic amplexus, similar to that present in some dendrobatids.

337 Because the male does not press the backside of his hands against the female's throat, we believe 338 this term should not be used (Wells, 1980). We therefore propose to name this behaviour a dorsal 
339 straddle. A dorsal straddle can be defined as a loose form of amplexus in which the male sits on

340 top of the female with his abdomen positioned on her lower dorsum. The male does not, however, 341 grasp the female under her armpits or head, but instead places his hands on the leaf, branch or 342 tree trunk the pair is sitting on (Figs. 1C and 2C). At the moment, dorsal straddle is known to 343 occur in N. humayuni only, but observations made in other Nyctibatrachus species (Biju et al., 344 2011) might also correspond with this newly-defined type of amplexus.

345 We speculate that a loose form of contact, with the male holding on to the substrate rather 346 than to the female, as seen during a dorsal straddle, might function to avoid falling and 347 interrupting mating. In Guibemantis depressiceps (Boulenger, 1882), which uses a head straddle 348 during amplexus, pulsing movements in the male flanks were observed during a short period of 349 physical contact (Blommers-Schlösser, 1975), similar to the ones observed here for 350 Nyctibatrachus humayuni (Video S4). The function of these pulsations is unclear, but similar 351 movements during amplexus have been observed in several other frog species (Savage, 1932; 352 Rabb \& Rabb, 1963; Weygoldt, 1976; Cui et al., 2010). It has been proposed that these 353 movements might stimulate ovulation by the female (Duellman \& Trueb, 1986: 71; Cui et al., 354 2010). 

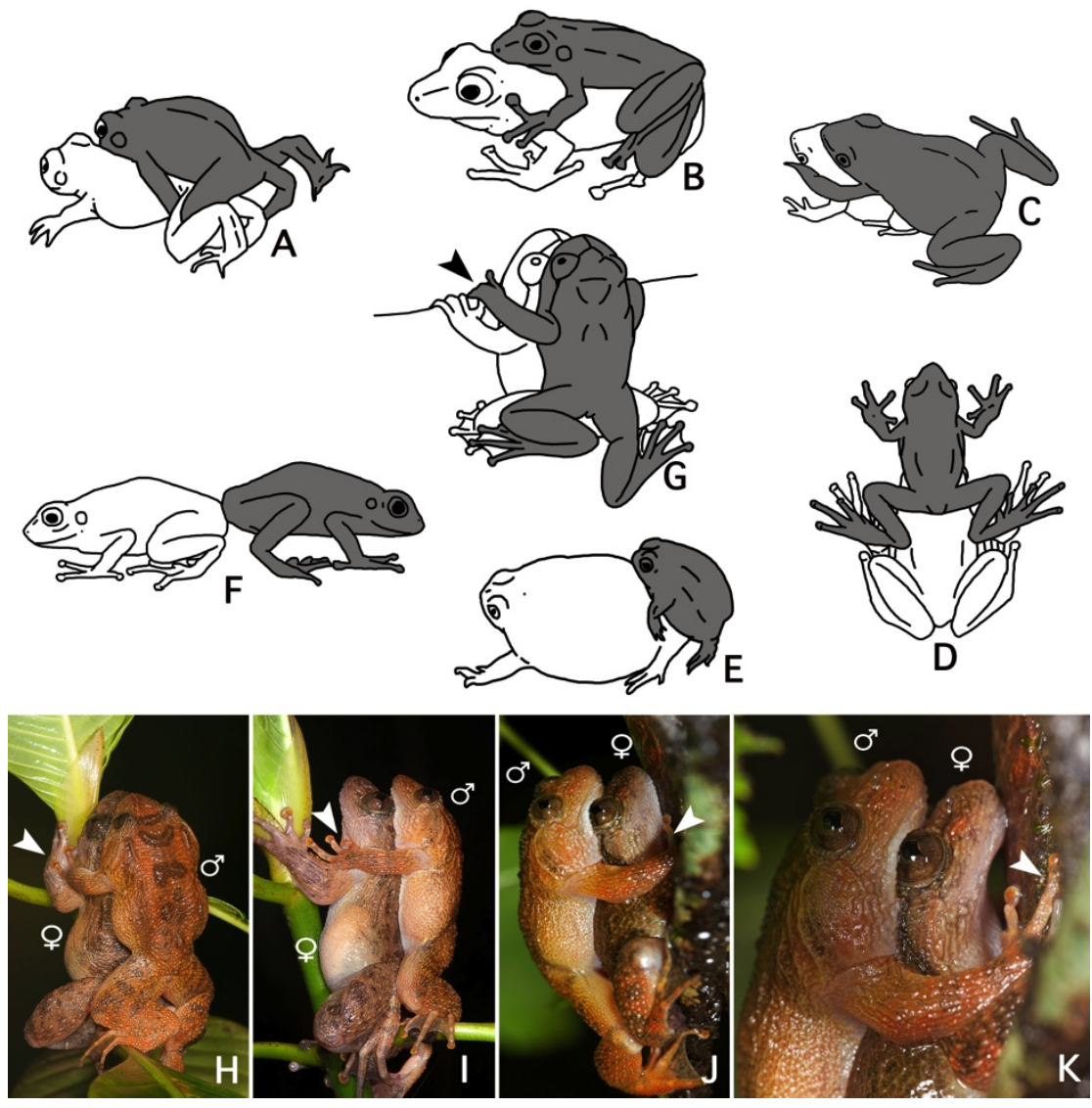

Figure $4 \mathrm{~A}$ comparison of known amplexus positions found in anuran amphibians with the new amplexus mode in Nyctibatrachus humayuni. (A-F) Known amplexus positions. (A) Inguinal. (B) Axillary. (C) Cephalic. (D) Head straddle. (E) Glued. (F) Independent (adapted from Duellman \& Trueb, 1986: 69). (G-I) Dorsal straddle, with the male's hands on sides of the female's head but not clasping the female. (G-H) Dorsal views. (I) Side view. (J-K) Dorsal straddle, with the male's hands holding a twig but not clasping the female. (J) Side view. (K) Close-up of the side view. Arrows indicate the male grasping position. The male is drawn grey and the female white.

357 Moment of fertilization

358 The loose contact during amplexus, and the lack of any physical contact between both sexes

359 during oviposition, that we have described is rarely seen among anurans. Our observations 360 significantly extend those made by Gramapurohit et al. (2011) of the same species.

361 Gramapurohit et al. (2011) observed a subsequent step after oviposition, in which the male 
362 placed himself on top of the eggs, and they considered this to be the moment of fertilization 363 (Gramapurohit, Gosavi \& Phuge, 2011). In our study, however, all clutches covered with a 364 Ziploc $^{\circledR}$ bag immediately after oviposition showed a 100\% fertilization rate, proving that semen 365 release must happen before clutch deposition, since the male dismounts the female just before 366 oviposition (Videos S5 and S7). This is remarkable, since amplexus is considered to increase 367 chances of successful fertilization by synchronizing egg deposition and semen release (Duellman 368 \& Trueb, 1986: 68-70). A complete lack of physical contact between male and female during 369 egg deposition is, therefore, rarely seen in anurans (Wells, 2007: 458, 513). Our findings are 370 inconsistent with the idea of the male fertilizing the eggs after deposition, as postulated by 371 Gramapurohit et al. (2011), and instead suggest that semen release must take place during the 372 dorsal straddle. We hypothesize that the male releases his sperm on the female's back and the 373 eggs are subsequently fertilized by the semen running down her back and hind legs. This 374 hypothesis is supported by the observation that female remains motionless after egg deposition, 375 for 479 seconds on average, with her hind legs stretched around the freshly deposited clutch 376 (Figs. 1E and 2D; Video S6). Furthermore, similar behaviour has been reported for Blommersia wittei (Guibé, 1974), B. blommersae (Guibé, 1975), Guibemantis depressiceps and G. liber 378 (Peracca, 1893), among others (Blommers-Schlösser, 1975; Glaw \& Vences, 2007: 144, 186, 200, 204; Altig, 2008). In these Malagasy frogs, males engage in a head straddle with females and dismount the female before she finishes egg deposition.

In Guibemantis depressiceps, multiple males were observed sitting on a female's head during a single egg deposition event, and the female exhibited lethargic behaviour, remaining stretched around the clutch for at least an hour after deposition had finished (Altig, 2008). For these mantellid frogs, the hypothesis of sperm running from the female back has also been assumed (Blommers-Schlösser, 1975; Altig, 2008). The exact moment of semen release could not be observed, as this was not possible with the naked eye during extremely wet field conditions, a problem also mentioned by Altig (2008). The male might release his semen just before dismounting the female. The eggs are then subsequently fertilized by sperm running down her back. Another possibility is that sperm is gradually released during amplexus and that the eggs are eventually deposited on top of the sperm. This last option has been observed in some species of Dendrobatoidea (Weygoldt, 1980). A few anurans make use of internal fertilization (Townsend 
392 et al., 1981; Stephenson \& Verrell, 2003), but for N. humayuni this is very unlikely as males lack

393 an intromittent organ and only limited contact between the two sexes exists.

394 In Nyctibatrachus petraeus there is no physical contact at all, and it is believed that the 395 male fertilizes the eggs after the female has deposited the clutch (Kunte, 2004). In this species 396 the female is reported to immediately leave after egg deposition (Kunte, 2004), contrasting with 397 our findings of $N$. humayuni females. Gururaja et al. (2014) do not mention the moment of 398 fertilization in N. kumbara, but it is unlikely to happen as in one of the methods described above. 399 Since the female deposits the eggs from an upside-down position, sperm cannot run down from 400 her back onto the eggs. Furthermore, the male only touches the eggs with his hands after 401 deposition, to cover them with mud (Gururaja et al., 2014). Future studies regarding the 402 reproductive behaviour of Nyctibatrachus should aim to pinpoint when semen is released and 403 how fertilization is achieved.

404

405 Egg development and egg attendance

406 Of the egg clutches monitored, $80 \%$ were eaten by predators before hatching. During a single 407 occasion, a Boiga sp. (tree snake) was observed eating a N. humayuni egg clutch (Video S10). Another water snake, Rhabdops olivaceus (Beddome, 1863), was frequently observed around the oviposition sites but no direct observation of predation was made. Gramapurohit et al. (2011) reported an egg stage duration of 11 to 13 days in their study population, which is much shorter than our observation of 18 to 21 days (Figs. $2 F-G$ ). An egg stage of 12 to 15 days and 8 days were observed for Nyctibatrachus petraeus and N. kumbara, respectively (Kunte, 2004;

413 Gururaja et al., 2014), while for N. aliciae an egg stage of 8 to 9 days was observed in a clutch 414 studied in captivity (Biju et al., 2011). As egg development duration is negatively correlated 415 with temperature within a certain optimal range (Duellman \& Trueb, 1986: 120-124; Wells, 416 2007: 124, 499), a higher number of observations and associated temperature data will be needed 417 to address this variation.

418 Males were seen each night in the same location, sitting near or on the developing 419 clutches that had resulted from earlier successful mating encounters. Egg attendance by the male, 420 or both male and female, is known for all Nyctibatrachus species in which reproductive 421 behaviour has been studied (Kunte, 2004; Biju et al., 2011; Gramapurohit, Gosavi \& Phuge, 422 2011; Gururaja et al., 2014). The function of egg attendance has not yet been studied in this 
423 genus, but it might prevent desiccation or reduce predation risk by arthropods, both of which 424 have already been confirmed in other anuran taxa (Crump, 2015). More specific parental care has 425 been documented for N. kumbara and N. grandis. Nyctibatrachus kumbara males cover the egg 426 clutch with mud, possibly preventing dehydration or providing camouflage against predation 427 (Gururaja et al., 2014). Males of N. grandis have been observed inflating their body upon 428 disturbance and making attempts to bite would-be predators, including human observers (Biju et 429 al., 2011).

431 Male call

432 The advertisement calls of only a few Nyctibatrachus species have been described (Kuramoto \& 433 Joshy, 2001; Gururaja et al., 2014). Gururaja et al. (2014) provide a brief description of the calls 434 of N. kumbara, N.jog and N. kempholeyensis (Rao, 1937), while a concise description of the call 435 of N. major Boulenger, 1882 is given by Kuramoto \& Joshy (2001). In N. kumbara and N. 436 kempholeyensis two distinct call types are distinguished; in $N$. kumbara one of these types was 437 produced more frequently when a female was present (Gururaja et al., 2014). Our recordings 438 were made in the absence of females. Therefore, we cannot exclude the possibility that in $N$. 439 humayuni too, distinct call types are present. The advertisement call from male N. humayuni described here is complex, consisting of an initial, unpulsed part with frequency modulation and a second, pulsed part without frequency modulation (Fig. 3A; Table S2). The call of N. jog also has a pulsed second part of the call (Gururaja et al., 2014). The call of $N$. humayuni can be distinguished from the call of $N$. major, the type I call of $N$. kumbara, and both types of call of $N$. kempholeyensis by call duration. With an average duration of $0.53 \mathrm{~s}$, the call is longer than the type I call of $N$. kumbara $(0.11 \mathrm{~s})$ and the call of $N$. major $(0.05 \mathrm{~s})$, while being substantially shorter than both call types of $N$. kempholeyensis $(5.17 \mathrm{~s}$ and $11.69 \mathrm{~s}$ for the type I and type II calls, respectively). Although call duration is similar between N. humayuni and the call of $N$. jog and the type II call of $N$. kumbara, the dominant frequency of $N$. humayuni calls is lower (1.33 $\mathrm{kHz})$ than that of $N$. kumbara type II calls $(1.53 \mathrm{kHz})$ and $N$. jog calls $(1.51 \mathrm{kHz})$.

Our results show a significant negative correlation between male body size and dominant 451 frequency (Table S3). This is the case for many anuran species, in which relatively larger 452 individuals' calls are characterized by relatively lower dominant frequencies. Larger males tend 
454 1971). In some species, females show a preference for low frequency calls and hence larger 455 males (Ryan, 1980; Wollerman, 1998). However, experimental studies have also shown that in 456 other species no preference is given to lower frequencies (Rosso, Castellano \& Giacoma, 2006). 457 Furthermore, female preference can vary between different populations within a single species 458 (Schrode et al., 2012). Within Nyctibatrachus, only a few species' calls have been described, and 459 no data on female preferences for spectral properties are available, making it impossible to draw 460 conclusions without further bioacoustic research on this group.

461

462 Female call

463 The discovery of a female call is remarkable, as this is rarely observed in frogs and toads. 464 Female calling behaviour has so far been reported in - to our knowledge - only 25 anurans, 465 representing less than $0.5 \%$ of the total of 6583 anuran species that are currently recognized $466(25 / 01 / 2016)$ (Frost, 2015). An overview of the species for which a female call has been reported 467 is given in Table S6. Female calling in Nyctibatrachus humayuni was observed only briefly and 468 on just four occasions over a total of 40 nights in the field, compared to the almost permanent 469 presence of male advertisement calls. The female call of $N$. humayuni is shorter and less complex than that of the male, consisting of a single, unpulsed note (Fig. 3B; Video S9). A short and less intense female call is also observed in other anuran species (Given, 1987; Emerson, 1992; Cui et al., 2010) and can, in part, be explained by the smaller size of laryngeal and oblique muscles of the female (Emerson \& Boyd, 1999). A female call is not known from any other species of Nyctibatrachus. Since documentation of the presence of female calls can be done with more confidence than their absence (Wells, 2007: 282), female vocalizations might be more common than currently believed, both among Nyctibatrachus species and across all anuran taxa more generally (Emerson \& Boyd, 1999).

Observed male responses to female calls include positive phonotaxis and changes in male vocalization rate (Emerson \& Boyd, 1999; Shen et al., 2008; Cui et al., 2010; Wang et al., 2010), suggesting that female vocalization is important in mate location and recognition. In this and other Nyctibatrachus species, calling males are often located in difficult to reach locations (e.g. vegetation overhanging the water) that might be accessed only by leaping towards them directly from the stream. It is likely that in such a situation the female will mainly rely on acoustic cues 
485 response to a female call might then prove beneficial in successfully locating a mate. This 486 hypothesis is only speculative at present, and additional observational and experimental studies 487 will be required to test it. Several other potential functions have been attributed to female calling 488 behaviour, such as signalling receptivity (Tobias, Viswanathan \& Kelley, 1998; Shen et al., 489 2008), distinguishing satellite males from territorial ones (Given, 1993) and inciting male-male 490 (Judge, Swanson \& Brooks, 2000) and female-female competition (Bush, 1997; Bosch, 2002).

491 Few of these hypotheses, however, have been tested experimentally (Wells \& Schwartz, 2007).

492 Both positive and negative phonotaxis has been observed in male Xenopus laevis (Daudin, 1802) 493 in response to two distinct female call types (Wang et al., 2010). Distinct female call types have 494 also been described for Alytes cisternasii (Márquez \& Verrell, 1991). Together, the scarce data 495 available on female vocal behaviour and the variability observed in male responses suggest a 496 complex of multiple, non-exclusive functions rather than a sole explanation.

497

498 Diversity in reproductive behaviours

499 Our results, combined with other recent behavioural studies (Kunte, 2004; Biju et al., 2011; 500 Gururaja et al., 2014), show a striking interspecific diversity in reproductive behaviours within 501 Nyctibatrachus. As the reproduction of many species in this genus has not yet been studied, the 502 extent of variation is likely to be even greater. Our limited understanding of this diversity is 503 evidenced by the high number of recent publications reporting new modes of breeding and associated reproductive behaviours (Zhang et al., 2012; Gururaja et al., 2014; Iskandar, Evans \& McGuire, 2014; Crump, 2015; Seshadri, Gururaja \& Bickford, 2015; Senevirathne et al., 2016). Within Nyctibatrachus, variation in the types of amplexus is especially remarkable, ranging from a normal axillary amplexus to a complete lack of physical contact between the sexes (Kunte, 2004; Gururaja et al., 2014). The use of amplexus is the ancestral state in anuran amphibians and enables juxtaposition of male and female cloaca to ensure successful fertilization

510 (Duellman \& Trueb, 1986: 68-70; Wells, 2007: 452-458). Secondary loss of amplexus was 511 already shown for a limited number of anuran taxa (Limerick, 1980; Brown et al., 2008; Zhang et 512 al., 2012) and a short, loose contact (head straddle) similar to the dorsal straddle reported here 513 for N. humayuni, was also found in several Mantidactylus species (Blommers-Schlösser, 1975; 514 Altig, 2008). Many males of both Mantidactylus and Nyctibatrachus possess distinct femoral 515 glands (Fig. S2B) (Vences et al., 2007; Biju et al., 2011). The function of these structures in 
516 Nyctibatrachus has not yet been addressed, but recently it was shown that the femoral glands of

517 Mantidactylus secrete volatile pheromones (Poth et al., 2012; Hötling et al., 2014). Further

518 studies are required to discover and understand the full extent of variation and the evolutionary

519 advantage of these highly diversified behaviours within Nyctibatrachus, especially regarding the

520 modification and loss of amplexus.

521

522 CONCLUSION

523 The breeding behaviour of Nyctibatrachus humayuni has several unique elements: a new type of 524 amplexus, the release of semen before oviposition and the presence of a female call. These 525 findings further highlight the tremendous variation present in the reproductive behaviour of 526 anuran amphibians. Nyctibatrachus frogs are one of several unique taxa in the Western Ghats 527 biodiversity hotspot, which is heavily threatened by anthropogenic activities (Myers et al., 2000; 528 Bossuyt et al., 2004; Van Bocxlaer et al., 2012). A good understanding of each species' ecology, 529 including reproduction, is of major importance for planning and successfully implementing 530 conservation strategies. Additional studies further exploring the unique and diverse behaviour in

531 Nyctibatrachus frogs are, therefore, badly needed. Special attention should be paid to describing 532 the amplexus type, determining the moment of fertilization and assessing the presence and 533 function of female calling behaviour.

534

535 Acknowledgments

536 We would like to thank Franky Bossuyt for valuable inputs during the initial phases of this study; 537 Kim Roelants for the basic illustrations used in Figure 1; our guide, Shanker Mama, for 538 assistance in the field; MM Anees and V Prasad for lab support; Ramit Verma for help in 539 compiling the videos; three anonymous reviewers and the academic editor for their comments 540 and suggestions to improve this manuscript. We are grateful to the Maharashtra State Forest 541 department for providing permits to conduct this study.

542

543

544

545

Additional Information and Declarations

545 Data Deposition

546 The following information was supplied regarding data availability: No additional raw data

547 beyond the Supplemental Information found in the body of the manuscript. 
551 Videos

552 Video S1 Male advertisement call.mov (20:00 sec)

553 Video S2 Female approaches calling male.mov (50:00 sec)

554 Video S3 Female touches male's head with her feet.mov (24:00 sec)

555 Video S4 Dorsal straddle: a new amplexus mode. mov (52:00 sec)

556 Video S5 Female's movements and dismounting of male.mov $(56: 00 \mathrm{sec})$

557 Video S6 Ovipostion: female deposits eggs.mov $(01: 10 \mathrm{sec})$

558 Video S7 Field experiment: Bagging of eggs.mov (10 sec)

559 Video S8 Male-male combat.mov (37 sec)

560 Video S9 Female call.mov $(27 \mathrm{sec})$

561 Video S10 Egg predation by snakes.mov (01:14 sec)

562

563

564

Audios

565 Audio S1 Male advertisement call: 10 filtered calls. wav

566 Audio S2 Male advertisement call: 10 unfiltered calls. wav

567 Audio S3 Female advertisement call: 6 unfiltered calls. wav

568

569

570

571

572

573 Tables

Figures

Figure S1 Study site and breeding habitat of Nyctibatrachus humayuni.

Figure S2 An adult male of Nyctibatrachus humayuni (in life).

574 Table S1 Description of the different properties that are used to describe the male and female calls.

575 Table S2 Overview of descriptive statistics of male Nyctibatrachus humayuni advertisement calls, based

576 on the values determined from a sample of eight individuals.

577 Table S3 Spearman Rank correlation between mean properties of male Nyctibatrachus

578 humayuni calls and SVL, mass and temperature (wet and dry) $(\mathrm{n}=8)$.

579 Table S4 Snout-Vent Length (SVL) and body mass of recorded male individuals, with 580 corresponding dry bulb and wet bulb temperature.

581 Table S5 Descriptive statistics of entire call of female Nyctibatrachus humayuni based on the 582 values determined from a sample of 1 individual (20 calls).

583 Table S6 Overview of anuran species in which a female call has been described.

584

585

586

REFERENCES

587 Altig R. 2008. Notes on the breeding biology of four species of mantellid frogs from 
588

589

590

591

592

593

594

595

596

597

598

599

600

601

602

603

604

605

606

607

608

609

610

611

612

613

614

615

616

617

618

619

620

621

622

623

624

625

626

627

Madagascar. Tropical Zoology 21:187-194.

Baker JMR. 1992. Body condition and tail height in great crested newts, Triturus cristatus. Animal Behaviour 43:157-159.

Beddome RH. 1863. Further notes upon the snakes of the Madras Presidency; with some descriptions of new species. Madras Quarterly Journal of Medical Science 6:41-48.

Bee MA, Suyesh R, Biju SD. 2013a. Vocal behavior of the Ponmudi Bush Frog (Raorchestes graminirupes): repertoire and individual variation. Herpetologica 69:22-35 DOI 10.1655/HERPETOLOGICA-D-11-00042.

Bee MA, Suyesh R, Biju SD. 2013b. The vocal repertoire of Pseudophilautus kani, a shrub frog (Anura: Rhacophoridae) from the Western Ghats of India. Bioacoustics 22:67-85 DOI 10.1080/09524622.2012.712750.

Bhaduri JL, Kripalani MB. 1955. Nyctibatrachus humayuni, a new frog from the western Ghats. Journal of the Bombay Natural History Society 52:852-859.

Biju SD, Van Bocxlaer I, Mahony S, Dinesh KP, Radhakrishnan C, Zachariah A, Giri V, Bossuyt F. 2011. A taxonomic review of the Night Frog genus Nyctibatrachus Boulenger, 1882 in the Western Ghats, India (Anura: Nyctibatrachidae) with description of twelve new species. Zootaxa 3029:1-96.

Biju SD, Van Bocxlaer I, Giri VB, Roelants K, Nagaraju J, Bossuyt F. 2007. A new nightfrog, Nyctibatrachus minimus sp. nov. (Anura: Nyctibatrachidae): The smallest frog from India. Current Science 93:854-858.

Blommers-Schlösser RMA. 1975. A unique case of mating behaviour in a Malagasy tree frog, Gephyromantis liber (Peracca, 1893), with observations on the larval development. Beaufortia 23:15-25.

Bosch J. 2002. The functionality of female reciprocal calls in the Iberian midwife toad (Alytes cisternasii): female-female acoustic competition? Naturwissenschaften 89:575-578 DOI 10.1007/s00114-002-0378-Z.

Bosch J, Márquez R. 2001. Female courtship call of the Iberian Midwife Toad (Alytes cisternasii). Journal of Herpetology 35:647-652 DOI 10.2307/1565904.

Bossuyt F, Meegaskumbura M, Beenaerts N, Gower DJ, Pethiyagoda R, Roelants K, Mannaert A, Wilkinson M, Bahir MM, Manamendra-Arachchi K, Ng PK, Schneider CJ, Oommen OV, Milinkovitch MC. 2004. Local endemism within the Western GhatsSri Lanka biodiversity hotspot. Science 306:479-481 DOI 10.1126/science.1100167.

Boulenger GA. 1882. Catalogue of the Batrachia Salientia s. Ecaudata in the Collection of the British Museum. Second Edition. London: Taylor and Francis.

Brzoska J, Walkowiak W, Schneider H. 1977. Acoustic communication in the Grass Frog (Rana t. temporaria L.): calls, auditory thresholds and behavioral responses. Journal of Comparative Physiology A Neuroethology, Sensory, Neural, and Behavioral Physiology 118: $173-186$.

Bush SL. 1997. Vocal behavior of males and females in the Majorcan Midwife Toad. Journal of Herpetology 31:251-257 DOI 10.2307/1565393. 
628 Bush SL, Dyson ML, Halliday TR. 1996. Selective phonotaxis by males in the Majorcan

629

630

631

632

633

634

635

636

637

638

639

640

641

642

643

644

645

646

647

648

649

650

651

652

653

654

655

656

657

658

659

660

661

662

663

664

665

666

667

midwife toad. Proceedings of the Royal Society B, London 263:913-917 DOI 10.1098/rspb.1996.0135.

Brown JL, Twomey E, Morales V, Summers K. 2008. Phytotelm size in relation to parental care and mating strategies in two species of Peruvian poison frogs. Behaviour 145:11391165 DOI 10.1163/156853908785387647.

Capranica RR. 1968. The Vocal Repertoire of the Bullfrog (Rana catesbeiana). Behaviour 31:302-325 DOI 10.1163/156853968X00306.

Charif RA, Waack AM, Strickman LM. 2010. Raven Pro 1.4 User's Manual. Ithaca, New York: The Cornell Lab of Ornithology.

Crump ML. 1974. Reproductive Strategies in a Tropical Anuran Community. University of Kansas Museum of Natural History, Miscellaneous Publication 61:1-68.

Crump ML. 2015. Anuran reproductive modes: evolving perspectives. Journal of Herpetology 49:1-16 DOI 10.1670/14-097.

Cui J, Wang Y, Brauth S, Tang Y. 2010. A novel female call incites male-female interaction and male-male competition in the Emei music frog, Babina daunchina. Animal behaviour 80:181-187 DOI 10.1016/j.anbehav.2010.05.012.

Das I, Kunte K. 2005. New species of Nyctibatrachus (Anura: Ranidae) from Castle Rock, Karnataka State, Southwest India. Journal of Herpetology 39:465-470 DOI: http://dx.doi.org/10.1670/198-04A.1.

Daudin F-M. 1802. "An. XI". Histoire Naturelle des Rainettes, des Grenouilles et des Crapauds. Quarto version. Paris: Levrault.

Duellman WE, Trueb L. 1986. Biology of Amphibians. Baltimore: The Johns Hopkins University Press.

Emerson SB. 1992. Courtship and vest-building behavior of a Bornean frog, Rana blythi. Copeia 1992:1123-1127.

Emerson SB, Boyd SK. 1999. Mating vocalizations of female frogs: Control and evolutionary mechanisms. Brain, Behavior and Evolution 53:187-197 DOI 10.1159/000006594.

Frost DR. 2015. Amphibian Species of the World: an Online Reference. Version 6.0. American Museum of Natural History, New York, USA. Available at http://research.amnh.org/herpetology/amphibia/index.html (accessed 25 January 2016).

Gerhardt HC. 1991. Female mate choice in treefrogs: static and dynamic acoustic criteria. Animal Behaviour 42:615-635.

Gerhardt HC, Huber F. 2002. Acoustic communication in insects and anurans: common problems and diverse solutions. Chicago: Chicago University Press.

Given MF. 1987. Vocalizations and Acoustic Interactions of the Carpenter Frog, Rana virgatipes. Herpetologica 43:467-481.

Given MF. 1993. Male response to female vocalizations in the carpenter frog, Rana virgatipes. Animal Behaviour 46:1139-1149 DOI 10.1006/anbe.1993.1303.

Glaw F, Vences M. 2007. A Field Guide to the Amphibians and Reptiles of Madagascar Third 
668

669

670

671

672

673

674

675

676

677

678

679

680

681

682

683

684

685

686

687

688

689

690

691

692

693

694

695

696

697

698

699

700

701

702

703

704

705

706

707

edition. Cologne: Vences \& Glaw Verlag.

Gollmann G, Benkö A, Hödl W. 2009. Release calls of female Bombina bombina (Anura : Bombinatoridae). Acta Herpetologica 4:113-115 DOI http://dx.doi.org/10.13128/Acta_Herpetol-2961.

Gosner KL, Rossman DA. 1959. Observations on the reproductive cycle of the Swamp Chorus Frog, Pseudacris nigrita. Copeia 1959:263-266 DOI 10.2307/1440411.

Gramapurohit NP, Gosavi SM, Phuge SK. 2011. Unique courtship and spawning behaviour in the wrinkled frog, Nyctibatrachus humayuni. Amphibia-Reptilia 32:333-339 DOI 10.1163/017353711X579786.

Guibé J. 1974. Batraciens nouveaux de Madagascar. Bulletin du Museum National d'Histoire Naturelle. Paris. Serie 3, Zoologie 171:1169-1192.

Guibé J. 1975. Batraciens nouveaux de Madagascar. Bulletin du Museum National d'Histoire Naturelle. Paris. Serie 3, Zoologie 323:1081-1089.

Gururaja KV, Dinesh KP, Priti H, Ravikanth G. 2014. Mud-packing frog: A novel breeding behaviour and parental care in a stream dwelling new species of Nyctibatrachus (Amphibia, Anura, Nyctibatrachidae). Zootaxa 3796:33-61 DOI http://dx.doi.org/10.11646/zootaxa.3796.1.2.

Haddad CFB, Prado CPA. 2005. Reproductive modes in frogs and their unexpected diversity in the Atlantic forest of Brazil. Bioscience 55:207-217 DOI http://dx.doi.org/10.1641/0006-3568(2005)055[0207:RMIFAT]2.0.CO;2.

Hötling S, Haberlag B, Tamm M, Collatz J, Mack P, Steidle JL, Vences M, Schulz S. 2014. Identification and synthesis of macrolide pheromones of the grain beetle Oryzaephilus surinamensis and the frog Spinomantis aglavei. Chemistry 20:3183-3191 DOI 10.1002/chem.201304414.

Iskandar DT, Evans BJ, McGuire J A. 2014. A novel reproductive mode in frogs: A new species of fanged frog with internal fertilization and birth of tadpoles. PLoS One 9: e115884 DOI 10.1371/journal.pone.0115884.

Inger RF, Shaffer HB, Koshy M, Bakde R. 1984. A report on a collection of amphibians and reptiles from the Ponmudi, Kerala, South India. Journal of the Bombay Natural History Society 81: 406-427.

IUCN. 2014. The IUCN Red List of Threatened Species. Version 2014.3 [Internet]. Available at www.iucnredlist.org (accessed 22 November 2014).

Jakob EM, Marshall SD, Uetz GW. 1996. Estimating fitness: a comparison of body condition indices. Oikos 77: 61-67.

Judge KA, Swanson SJ, Brooks RJ. 2000. Rana catesbeiana (Bullfrog). female vocalization. Herpetological Review 31:236-237.

Kunte K. 2004. Natural history and reproductive behavior of Nyctibatrachus cf . humayuni (Anura: Ranidae). Herpetological Review 35:137-140.

Kuramoto M, Joshy SH. 2001. Advertisement call structures of frogs from Southwestern India, with some ecological and taxonomic notes. Current Herpetology 20:85-95 DOI 
724

725

726

727

728

729

730

731

732

733

734

735

736

737

738

739

740

741

742

743

744

745

746

747

\section{http://doi.org/10.5358/hsj.20.85.}

Limerick S. 1980. Courtship behavior and oviposition of the poison-arrow frog Dendrobates pumilio. Herpetologica 36:69-71.

Martin WF. 1971. Mechanics of sound production in toads of the genus Bufo: passive elements. Journal of Experimental Zoology 176:273-293.

Márquez R, Verrell P. 1991. The courtship and mating of the Iberian midwife toad Alytes cisternasii (Amphibia: Anura: Discoglossidae). Journal of Zoology 225:125-139 DOI:10.1111/j.1469-7998.1991.tb03806.x.

Myers N, Mittermeier RA, Mittermeier CG, Fonseca GAB, Kent J. 2000. Biodiversity hotspots for conservation priorities. Nature 403:853-858 DOI 10.1038/35002501.

Peracca MG. 1893. Descrizione di nuove specie di rettili e anfibi di Madagascar. Bollettino dei Musei di Zoologia e Anatomia Comparata della R. Universita di Torino 156:1-16.

Poth D, Wollenberg KC, Vences M, Schulz S. 2012. Volatile amphibian pheromones: macrolides from mantellid frogs from Madagascar. Angewandte Chemie International Edition in English 51:1-5 DOI 10.1002/anie.201106592.

Rabb GB, Rabb MS. 1963. On the behavior and breeding biology of the African pipid frog Hymenochirus boettgeri. Zeitschrift für Tierpsychologie 20:215-241.

Rao CRN. 1937. On some new forms of Batrachia from S. India. Proceedings of the Indian Academy of Sciences Section B 6:387-427.

Rosso A, Castellano S, Giacoma C. 2006. Preferences for call spectral properties in Hyla intermedia. Ethology 112:599-607 DOI 10.1111/j.1439-0310.2005.01186.x.

Ryan MJ. 1980. Female Mate Choice in a Neotropical Frog. Science 209:523-525 DOI 10.1126/science.209.4455.523.

Savage JM. 2002. The amphibians and reptiles of Costa Rica: a herpetofauna between two continents, between two seas. Chicago and London: The University of Chicago Press.

Savage RM. 1932. The spawning, voice, and sexual behaviour of Bombina variegata variegata. Journal of Zoology 4:889-898 DOI 10.1111/j.1096-3642.1932.tb01570.x.

Schrode KM, Ward JL, Vélez A, Bee MA. 2012. Female preferences for spectral call properties in the western genetic lineage of Cope's gray treefrog (Hyla chrysoscelis). Behavioral Ecology Sociobiology 66:1595-1606 DOI 10.1007/s00265-012-1413-5.

Senevirathne G, Garg S, Kerney R, Meegaskumbura M, Biju SD. 2016. Unearthing the Fossorial Tadpoles of the Indian Dancing Frog Family Micrixalidae. PLoS ONE 11(3): e0151781 DOI 10.1371/journal.pone.0151781.

Seshadri KS, Gururaja KV, Bickford DP. 2015. Breeding in bamboo: a novel anuran reproductive strategy discovered in Rhacophorid frogs of the Western Ghats, India. Biological Journal of the Linnean Society 114:1-11 DOI 10.1111/bij.12388.

Shen J-X, Feng AS, Xu Z-M, Yu Z-L, Arch VS, Yu X-J, Narins PM. 2008. Ultrasonic frogs show hyperacute phonotaxis to female courtship calls. Nature 453:914-916 DOI 10.1038/nature 06719 .

Stephenson B, Verrell P. 2003. Courtship and mating of the tailed frog (Ascaphus truei). 
759

760

761

762

763

764

765

766

767

768

769

770

771

772

773

774

775

776

777

778

779

780

781

782

783

784

785

786 Journal of Zoology 259:15-22 DOI 10.1017/S095283690200331X.

Stewart MM, Rand AS. 1991. Vocalizations and the defense of retreat sites by male and female frogs, Eleutherodactylus coqui. Copeia 1991:1013-1024.

Tobias ML, Viswanathan SS, Kelley DB. 1998. Rapping, a female receptive call, initiates male-female duets in the South African clawed frog. Proceedings of the National Academy of Sciences of the United States of America 95:1870-1875 DOI 10.1073/pnas.95.4.1870.

Townsend DS, Stewart MM, Pough FH, Brussard PF. 1981. Internal fertilization in an oviparous frog. Science 212:469-471 DOI 10.1126/science.6894203.

Van Bocxlaer I, Biju SD, Willaert B, Giri VB, Shouche YS, Bossuyt F. 2012. Mountainassociated clade endemism in an ancient frog family (Nyctibatrachidae) on the Indian subcontinent. Molecular Phylogenetics and Evolution 62:839-847 DOI 10.1016/j.ympev.2011.11.027.

Vences M, Wahl-Boos G, Hoegg S, Glaw F, Spinelli Oliveira E, Meyer A, Perry S. 2007. Molecular systematics of mantelline frogs from Madagascar and the evolution of their femoral glands. Biological Journal of the Linnean Society 92:529-539 DOI 10.1111/j.1095-8312.2007.00859.x.

Wang Y, Cui J, Yu X, Tang Y. 2010. Male phonotropism and answer calls elicited by female vocalizations in the African Clawed Frog, Xenopus laevis. Journal of Herpetology 44:475-479 DOI 10.1670/09-055.1.

Wells KD. 1980. Behavioral ecology and social organization of a dendrobatid frog (Colostethus inguinalis). Behavioral Ecology Sociobiology 6:199-209 DOI 10.1007/BF00569201.

Wells KD. 2007. The Ecology and Behaviour of Amphibians. Chicago: The University of Chicago Press.

Wells KD, Schwartz JJ. 2007. The behavioral ecology of anuran communication. In: Narins PM, Feng AS, Fay RR, Popper AN, eds. Hearing and Sound Communication in Amphibians. New York: Springer, 44-86.

Weygoldt P. 1976. Beobachtungen zur Biologie und Ethologie von Pipa (Hemipipa) carvalhoi Mir. Rib. 1937. (Anura, Pipidae). Zeitschrift für Tierpsychologie 40:80-99.

Weygoldt P. 1980. Complex brood care and reproductive behavior in captive Poison-Arrow Frogs, Dendrobates pumilio O. Schmidt. Behavioral Ecology and Sociobiology 7:329-332.

Wollerman L. 1998. Stabilizing and directional preferences of female Hyla ebraccata for calls differing in static properties. Animal Behaviour 55:1619-1630 DOI 10.1006/anbe.1997.0697.

Zhang L, Yang J, Lu Y, Lu X, Chen X. 2012. Aquatic eggs are fertilised by multiple males not engaged in amplexus in a stream-breeding frog. Behavioural Processes 91:304-307 DOI 10.1016/j.beproc.2012.08.003. 
